\title{
Knowledge Conversion and Transfer: A Mathematical Interpretation
}

\author{
Firas M. Alkhaldi and Mohammad Olaimat \\ Arab Academy for Banking and Financial Sciences, \\ Amman Jordan
}

\section{falkhaldi@aabfs.org mohmadolaimat2000@yahoo.com}

\begin{abstract}
In this paper, the authors attempt to redefine the knowledge conversion and transfer processes to facilitate clearer, scientific and manageable knowledge activities. The authors examine carefully the conversion process of knowledge; i.e. tacit knowledge to explicit knowledge and finally to information and vise versa. They introduced a mathematical interpretation and representation of knowledge conversion and brought to light a new concept labeled as "Infoledge". The mathematical representation of knowledge transfer represents a new trend in this area that can be utilized in wider domains, i.e. human sciences, cognitive science, artificial intelligence and so on, through exploiting this view in related applications.
\end{abstract}

Key words: knowledge, information, infoledge, intuition, knowledge conversion, knowledge transfer process.

\section{Knowledge and Information}

Knowledge and information are often used interchangeably; in order to isolate any misunderstanding a clear distinction between the two is needed. Nonaka (1994) defines information as a flow of messages and meaning, while knowledge is creation, and organization, the flow of information. Nonaka and Takeuchi (1995) described the similarity and differences between the two concepts; knowledge, unlike information, is about beliefs and commitment and is about action, where knowledge is a product of a particular instance and perspective. Knowledge, like information, is about meaning, which is context-specific and relational. Sanchez (2001) defined information as the meaning that is attributed to some data, where data are defined by Davenport and Prusak (1998, p. 2), as "a set of discrete, objective facts about events". In which comparing data with other data derives meaning, where knowledge is "a set of beliefs about casual relationships in the world and an organization" (Sanchez, 2001, p.5). Boisot and Griffith (2001) defined information as the meaning that is related to an observer's prior expectation when it is extracted from incoming data, where knowledge is the individual interpretation of the meaning of informa-

Material published as part of this journal, either on-line or in print, is copyrighted by the Informing Science Institute. Permission to make digital or paper copy of part or all of these works for personal or classroom use is granted without fee provided that the copies are not made or distributed for profit or commercial advantage AND that copies 1) bear this notice in full and 2) give the full citation on the first page. It is permissible to abstract these works so long as credit is given. To copy in all other cases or to republish or to post on a server or to redistribute to lists requires specific permission and payment of a fee. Contact Publisher@InformingScience.org to request redistribution permission. tion that modifies the individual beliefs that reside in him. Knapp (1998, p. 4) sees knowledge as "information in action, where information is mindfully applied for a specific purpose and/or during a specific task". Davenport and Prusak (1998, p. 3) defined information as "data that makes the difference"; in other words, information viewed as a message is meant to shape up the individual that gets it, to make some differ- 
ence in his prospect and insight and it only becomes knowledge when it conveys meaning for the receiver. Bailey and Clarke (2000) defined knowledge as "usable ideas", ideas which are current, relevant and actionable.

\section{Data-Wisdom Conversion Spectrum}

Building on arrangement presented in the pervious section, and in order to introduce a later concept "Infoledge", a clear representation of the Data-Wisdom conversion process is needed. Based on autopoietic epistemology as argued by Maturana and Varela (1980), they provide a fundamentally different understanding of the input into a system. Autopoietic systems are thus both closed and open. Open to data, but closed to information and knowledge, both of which have to be interpreted inside the system where input is regarded as data only. Alkhaldi (2005) refers to the Autopoietic system as the human mental framework. Autopoietic systems are self-referring and the world is thus not seen as fixed and objective; the world is constructed within the system and it is therefore not possible to "represent" reality. Knowledge is private, and is thus accumulated within the system. Alkhaldi (2005) presented a methodical process (see Figure 1), where he indicated that once knowledge articulation is started by the knowledge owner (sender), data will start to be accumulated and mounted by the knowledge recipient (receiver). A meaning will start to be formulated in the mental framework (the system as referred by Maturana and Varela, 1980) of the recipient through the processing of the accumulated data and thus creates information. While the knowledge owner continues the articulation process, the recipient keeps adding meaning (reflect) to the previous concept obtained thereby converting it into direction. By this stage, the infoledge will be conceived, which is, in simple terms, information with direction. In order to reach the knowledge stage, the recipient has to self-experience infoledge through the notion of doing (acting upon, perform) where he can validate the output of the pervious stage. Hence, knowledge is conceived and internalized with the recipient as the new knowledge owner. Knowledge can be viewed through experience, since the latter can provide the historical perception from which we perceive and comprehend the new circumstances and events. Huseman and Goodman (1999, p. 108) put it as "Experience is the essential bridge between what happened in the past and what is happening in the present,... experience also holds value for critical understanding it adds to a new situation".

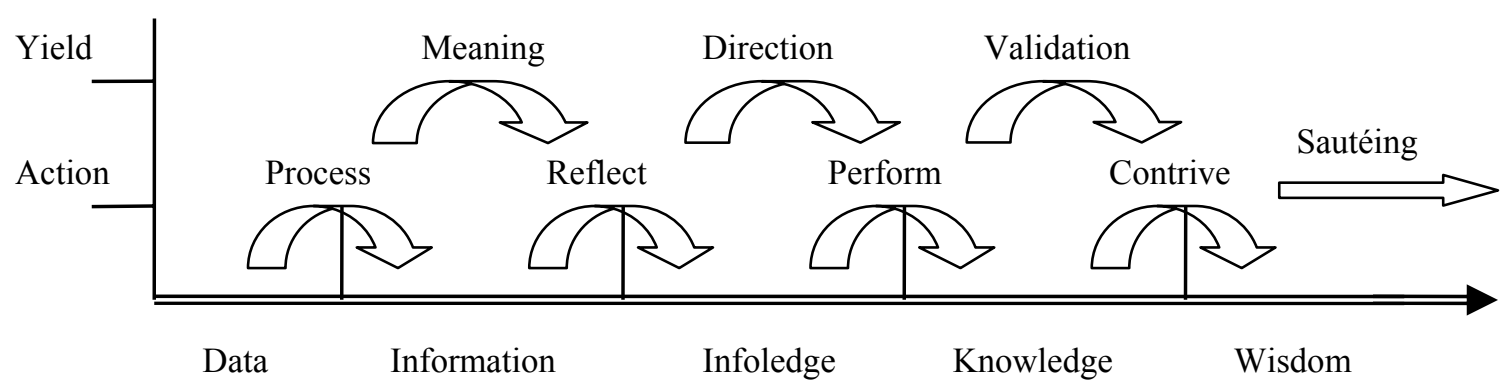

Figure 1: Data-Wisdom conversion Spectrum (adapted from Alkhaldi, 2005)

\section{Knowledge Transfer Process}

A number of researchers have looked at two dimensions of knowledge: explicit and tacit (Kogut \& Zander, 1996; Nelson \& Winter, 1982; Polanyi, 1966). Explicit knowledge is easy to define, capture and transfer in different formats, whereas tacit knowledge is difficult to codify and transfer, because it is deeply rooted in individual minds and individuals often cannot easily articulate 
their knowledge bases. Okafar and Osuagwa (2006) stated that direct elicitation techniques are used to elucidate explicit knowledge where the source of this knowledge is expected to be communicative, willing and can articulate its knowledge. On the other hand, indirect methods are more adapted to situations of tacit knowledge, i.e. role playing. Drawing on Michael Polanyi's (1966) distinction between tacit knowledge and explicit knowledge, an interesting knowledge creation model from Nonaka and Takeuchi (1995) viewed tacit knowledge and explicit knowledge as separate but mutually complementary entities. Their model shows that the basis of organizational knowledge creation is in the conversion of tacit knowledge into explicit knowledge and visa versa. Organizational knowledge is created based on the interaction and conversion between the two types of knowledge (tacit and explicit) in a spiral manner. A process model of knowledge creation develops on the critical presupposition that individual knowledge is created and enlarged by means of a social interaction between tacit and explicit knowledge. This interaction is called knowledge conversion. The interaction between the two main types of knowledge allows positing four different modes of knowledge conversion. According to Nonaka (1994) and Nonaka and Takeuchi (1995), the knowledge creation process takes place through four modes of knowledge conversion.

The conversion process can be from tacit to tacit exemplified in socialization mode, which can be seen as sharing ideas, mental model and technical skills through interaction between organizational members or a focus group. Tacit to explicit exemplified in externalization mode which occurs when tacit knowledge is made explicit in the form of metaphors, analogies, hypotheses and models. It is the attempt to conceptualize our image, and then express it in language, where at this mode of knowledge conversion, information is mainly used to compile different analogies and metaphors for the creation of new knowledge (Nonaka \& Takeuchi, 1995, 1996). Explicit to explicit occurs in combination mode where it is the process of conglomerating various bodies of existing explicit knowledge that leads to the creation of new explicit knowledge (Alkhaldi 2003). Combination is a common form of knowledge creation and transfer such as learning in schools (Choo, 1998). Nonaka and Takeuchi, (1995) stated that explicit to tacit occurs in internalization mode that is the process of embodying explicit knowledge into tacit knowledge. Information sharing provides the ground for internalizing explicit knowledge into tacit actions. It is closely related to learning by doing. It is rather important to indicate that the conversion does not occur within individuals but between individuals within an organization.

Nonaka and Takeuchi's model for knowledge conversion and creation within an organization takes a form of spiral process in which each type of knowledge, tacit or explicit, can be converted and the process can be viewed as a continuous learning process (see Figure 2). Likewise, organizational knowledge creation demands an interaction and conversion between both tacit and explicit knowledge and between individuals and groups in the organization. To conclude, different kinds of knowledge being created from the four modes of interaction between tacit and explicit knowledge, i.e. the four manner of creating knowledge, together form a kind of spiral of knowledge (Nonaka and Takeuchi, 1995) which starts from socialization and moves to externalization to combination to internalization to socialization, and so on. In the four different situations, different kinds of knowledge are being created, over and over again. From the previous discussion we can see that there are many more distinctions that can be made, but the main focus of all these distinctions, however, is that between tacit and explicit knowledge. The process model of knowledge creation that Nonaka and Takeuchi (1995) developed has the advantage that it is a dynamic model of knowledge but lacks a critical transitional stage that must occur, in particular, when tacit knowledge is converted into explicit knowledge and visa versa. The researcher will demonstrate in a mathematical interpretation to illustrate the shortcomings of the Nonaka and Takeuchi knowledge conversion model as stated earlier. 


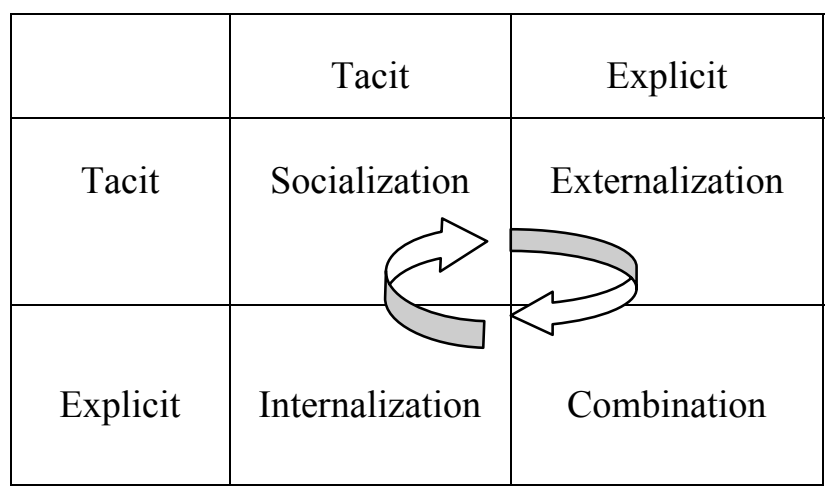

Figure 2: Knowledge conversion and the spiral of knowledge (Adapted from Nonaka \& Takeuchi, 1995)

\section{Mathematical Interpretation: Definitions}

Following the work of Salas and Etgen (1998), the following definitions are utilized.

\section{Definition 1: The limit of a function}

Let $\mathrm{f}$ be a function defined at least on some set of the form

$$
(c-p, c) U(c, c+p) \text {, with } p>0 \text {. }
$$

Then $\lim f(\mathrm{x})=\mathrm{L}$

$$
\mathrm{x} \rightarrow \mathrm{c}
$$

For each $\quad \mathrm{e}>0$, there exists a $\mu>0$ such that

$$
\text { if } 0<|\mathrm{x}-\mathrm{c}|<\mu,|f(\mathrm{x})-\mathrm{L}|<\mathrm{e} .
$$

\section{Definition 2:Left-hand limit}

Let $\mathrm{f}$ be a function defined at least on an interval of the form

$$
\text { (c-p,c) with } \mathrm{p}>0 \text {. Then } \lim f(\mathrm{x})=\mathrm{L}
$$

$$
\mathrm{x} \rightarrow \mathrm{c}-
$$

For each $\quad \mathrm{e}>0$, there exists a $\mu>0$ such that

$$
\text { If } \mathrm{c}-\mu<\mathrm{x}<\mathrm{c} \text {, then }|f(\mathrm{x})-\mathrm{L}|<\mathrm{e} \text {. }
$$

Definition 3: Newton -Raphson approximation, as sited in Salas and Etgen (1998)

Let $\mathrm{h} \neq 0$, the difference $f(\mathrm{x}+\mathrm{h})-f(\mathrm{x})$ is called the increment of $\mathrm{f}$ from $\mathrm{x}$ to $\mathrm{x}+\mathrm{h}$, and is denoted by $\Delta \mathrm{f}$ :

$$
\Delta f=f(\mathrm{x}+\mathrm{h})-f(\mathrm{x})
$$

The product $\mathrm{f}^{\prime}(\mathrm{x}) \mathrm{h}$ is called the differential of $f$ at $\mathrm{x}$ with increment $\mathrm{h}$, and is denoted by $d f$ :

$$
d f=\mathrm{f}^{\prime}(\mathrm{x}) \mathrm{h}
$$

$(\Delta f-d f) / \mathrm{h}$ tends to 0 as $\mathrm{h} \rightarrow 0 . \quad d f$ in the sense that $\approx \Delta f$

\section{Knowledge Maturity}

The inputs of knowledge to the human being are: sight, listening, touch, taste, smell, where the human knowledge results from one or more of these inputs, so each input participating in overall accumulated knowledge as parts, where each part can be denoted by $\Delta$ (delta). 
$\Delta \mathrm{K}=\Delta$ Sight $+\Delta$ Listening $+\Delta$ Touch $+\Delta$ Taste $+\Delta$ Smell, where

$\Delta$ Vision: Knowledge part that is obtained by the sight.

$\Delta$ Listening: Knowledge part that is obtained by the listening.

$\Delta$ Touch: Knowledge part that is obtained by the touch (hands, legs, any thing that can be considered a human communication interface)

$\Delta$ Taste: Knowledge part that is obtained by the taste.

$\Delta$ Smell: Knowledge part that is obtained by the smell.

$\Delta \mathrm{K}$ : Amount of Knowledge obtained from accumulation of the above $\Delta$ 's by minimizing $\Delta \mathrm{K}$ as possible then

$\Delta K \approx d K$ (Definition 3)

$d K$ : is a small snapshot of the knowledge through which we can infer something about the knowledge.

So

$d K=d$ Sight $+d$ Listening $+d$ Touch $+d$ Taste $+d$ Smell

Integrate the above equation (boundless integration)

$\int d K=\int d$ Vision $+\int d$ Listening $+\int d$ Touch $+\int d$ Taste $+\int d$ Smell $\quad$ Eq (0)

Equation (0) spells out how the knowledge maturity process is realized.

\section{Intuition Concept}

Intuition represents the way how the human view certain concept, but this process (view formulation) depends on the base knowledge "mental framework" within human mind toward this concept, which is what we call the tacit knowledge related to this concept This view was supported Davenport and Prusak (1998, p. 10) where they define intuition or rules of thumb as "flexible guides to action that developed through trial and error and over a long experience and observation". Huseman and Goodman (1999, p. 112) defined intuition as an "unconscious decision maker born of experience and refined through trial and error". Thus intuition is a critical part of knowledge and according to Alkhaldi (2003) intuition provides speed since it allows the knower to deal quickly with new situation and he does not need to relearn the aspect of a new situation. Based on the above arrangement tacit knowledge can be suggested to represent intuition mathematically by the following equation:

Intuition $=\int$ tacit, at some point of time

This equation doesn't take into consideration how far this tacit knowledge is from the final intuition. Consider Figure 3.

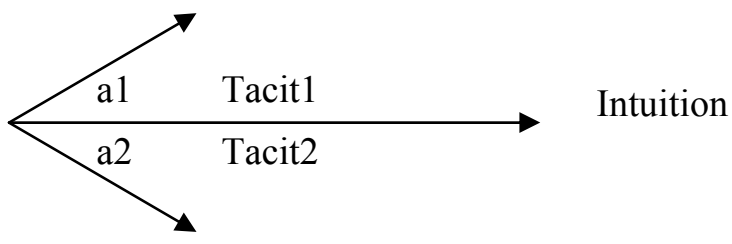

Figure 3: Intuition formulation 
a1, a2 represent the deviation of the intuition from tacit land tacit2 respectively. Hence in this context:

$$
\text { Intuition }=\text { tacit } 1 * \mathrm{a} 1+\operatorname{tacit} 2 * \mathrm{a} 2+\ldots+\text { tacit } n * \text { an } \quad \text { Eq (2) }
$$

Where $n$ denotes the tacit knowledge sharing in intuition formulation.

The following can be inferred from Eq (2):

- Human intuition for certain situation is the net resultant of a group of related tacit knowledge.

- Time plays a vital role in determining intuition since it is a maturing process related to the accumulating of tacit knowledge during many periods of times.

- As tacit knowledge increases, the intuition gets closer to the exact meaning. This stage is called wisdom.

- Intuition is changing frequently due to its ingredients.

From this equation, it appears that learning impact has the main role in building intuition. So intuition can be represented as a function of time and the tacit knowledge (within a specific domain) by taking into account the definition of uncertainty as the difference between the knowledge required to make a decision and the knowledge a decision maker has at the time of the problem (Falzon, Zhang, \& Davies. 2000). The above results are supported by Jamieson and Hyland (2006) who state that decision makers apply cognitive filters or biases to simplify the decision making process.

\section{Knowledge Transition Stages}

The following chart (Figure 4) represents the behavior of human intuition with respect to time during knowledge transition from one person to another.

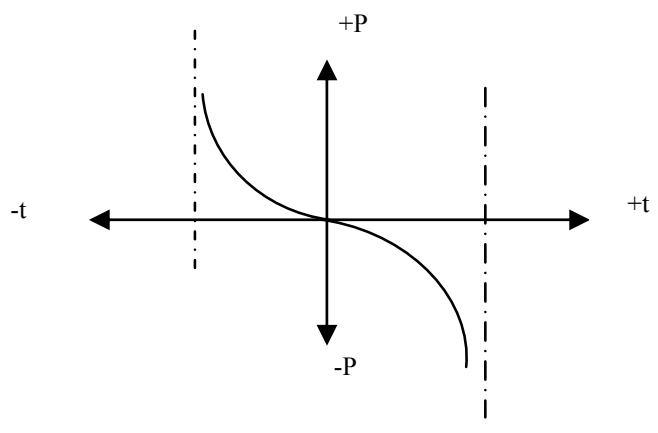

Figure 4: Knowledge transition

$+\mathrm{P}:$ the sender (human)

-P: the receiver (human)

$+\mathrm{t}$ : the time which the knowledge is formed within its receiver (-P)

$-\mathrm{t}$ : the time which the knowledge is processed (converted) within its owner mind $(+\mathrm{P})$

Initially, we must first identify the relationship between intuition and tacit knowledge. With respect equation (1), it can easily be noted that intuition deals with tacit knowledge utilized when 
needed where the need to represent a new situation calls for a decision. So intuition is built on the tacit knowledge content — not the opposite. This intuition extends the tacit knowledge value and will increase the knowledge curve. The knowledge curve represents the level at which any human can form a certain knowledge base. Now let us turn to the process through which knowledge is transferred, (see figure 5). This figure shows the first quadrant of the previous chart for any time $\mathrm{t} 1$, where the context of the knowledge is different from that at time $\mathrm{t} 2$. The curve in Figure 5 represents the behavior of intuition function.

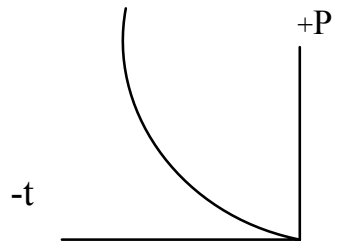

\section{Figure 5: Externalization process}

Alkhaldi (2003) stated that conceptual knowledge represents the type of knowledge that emerges from the externalization processes, where the objectives of those processes are to create a concept, which is revealed in Figure 5. A concept passes through the transition mode consisting of two stages before its creation. The first stage starts when the human is willing to express and articulate this concept with the sender's tacit knowledge from within a specific knowledge context. The researchers will represent this tacit mathematically by the following equation:

$$
\begin{aligned}
& \mathrm{Lim} \text { intuition }=\text { Tacit of }+\mathrm{P} \text {, for any time }(\mathrm{t} 1) \\
& \mathrm{t} \rightarrow \mathrm{t} 1
\end{aligned}
$$

Also, Alkhaldi (2003) and Nonaka (1994) asserted that socialization is the process of sharing knowledge and experience with the use of a language. Using this context, it can be inferred that sharing process starts from a knowledge type (let us denote it as the externalization process) that can be understood by the receiver (let us denote it by internalization process). So sharing and understanding the processes of externalization and internalization begins once a first pass of the knowledge is released from its owner (sender) to be re-formed by the receiver. Example: if someone says to another: I am a student in the university, then the later will receive this statement as follows:

I am: it is the one who is talking.

A student: not something else, i.e., teacher.

University: not school, training center... etc.

So, each part of the above statement appears to the receiver as something new (data; refer to autopoetic epistemology), and she/he deals with it after processing it as information (in its abstract view). On the other side, the sender looks at the above statement as follows:

I am: I am a student in the university - a student in the university (- denotes the minus sign)

A student: I am a student in the university - in the university

University: I am a student in the university (here is the complete statement)

We are most likely in a situation which expresses a pushing process (externalization through articulation), that is, one part of knowledge pushing the one it follows. This can be seen as stage articulation process, referring to Figure 6. It can be noted that this process of knowledge pushing is the result of externalization process as expressed by Alkhaldi (2003). The pushing process 


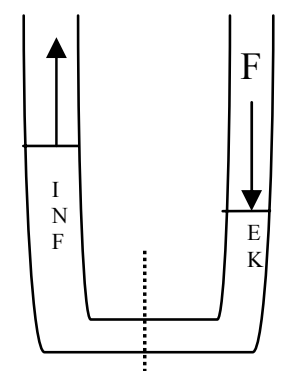

E.K: Explicit knowledge INF: information

Figure 6: Explicit knowledge conversion represents the process of how explicit knowledge formed (owner's view). This is the starting stage of socialization, according to the receiver and the ending stage of externalization according to the sender. The question that may be asked is: why do we call it a stage rather than a point? The analogy presented above answers this question. Again we will refer to "pushing process" concept: pushing stands for getting close to some point through articulation. We will define this point as the point at which the sender completes expressing his/her knowledge (e.g. I am a student in the university). Mathematically, the pushing process can be represented by the limits concept. Explicit knowledge can be represented mathematically by the following expression:

Lim intuition $=$ Explicit knowledge $\quad$ Eq (4)

$\mathrm{t} \rightarrow 0$ - $\quad$ (The minus sign is for the left direction, definition 2)

In it higher completeness stage, explicit knowledge articulated by the owner can be seen as infoledge of the receiver. In another words, after

knowledge articulation by the sender and before knowledge comprehension (validating) by the receiver, infoledge materializes. At this stage the knowledge needs to be extorted from one context and be converted and adapted to another context. The adaptability depends on the way how this context will be interpreted. Fernie, Green, Weller, and Newcombe (2003) claimed that this interpretation may alter the original knowledge to the extent that it symbolizes a different knowledge. The researchers call it infoledge due to its different views according to sender and receiver. Just imagine a coin with two faces (head and tails). To elaborate more, infoledge emerges as the sender passes information through the knowledge space to the receiver. To the sender it is his/her knowledge (explicit knowledge) that he/she was able to articulated through language. To the receiver it is an information with direction that has not been experienced, tested, or lived by $\mathrm{him} /$ her, and yet it cannot be classified as knowledge see Figure 7. This view is supported by Libeskind (1996, p. 94) when he defines knowledge as "information whose validity has been established through tests of proof". The reason the researchers called it infoledge is the fact it is extracted out of the concept of doing, where knowledge by fact requires doing to be comprehended. Alkhaldi (2003) stated that tacit knowledge is distributed in the totality of the individual's action experience and is action centered. This view is consistent with the views of the philosopher Michael when he argues that tacit knowledge is highly personal and deeply rooted in action and in the individual's commitment to a specific context. Infoledge can be argued to be less valuable than knowledge because is has been extracted from the doing notion, and yet, it can also be considered to be of a greater value of information because it still has the residual of the doing context of the knowledge owner (sender). Infoledge is mental model oriented, as argued by Maqsood, Finegan, and Walker (2004) as the determinant of how the environmental motivations will be interpreted and incorporated or synthesized. Giving this context, infoledge can be modeled logically, see Equation 5.

$$
\text { Knowledge }>\text { Infoledge } \geq \text { information } \quad \text { Eq (5) }
$$




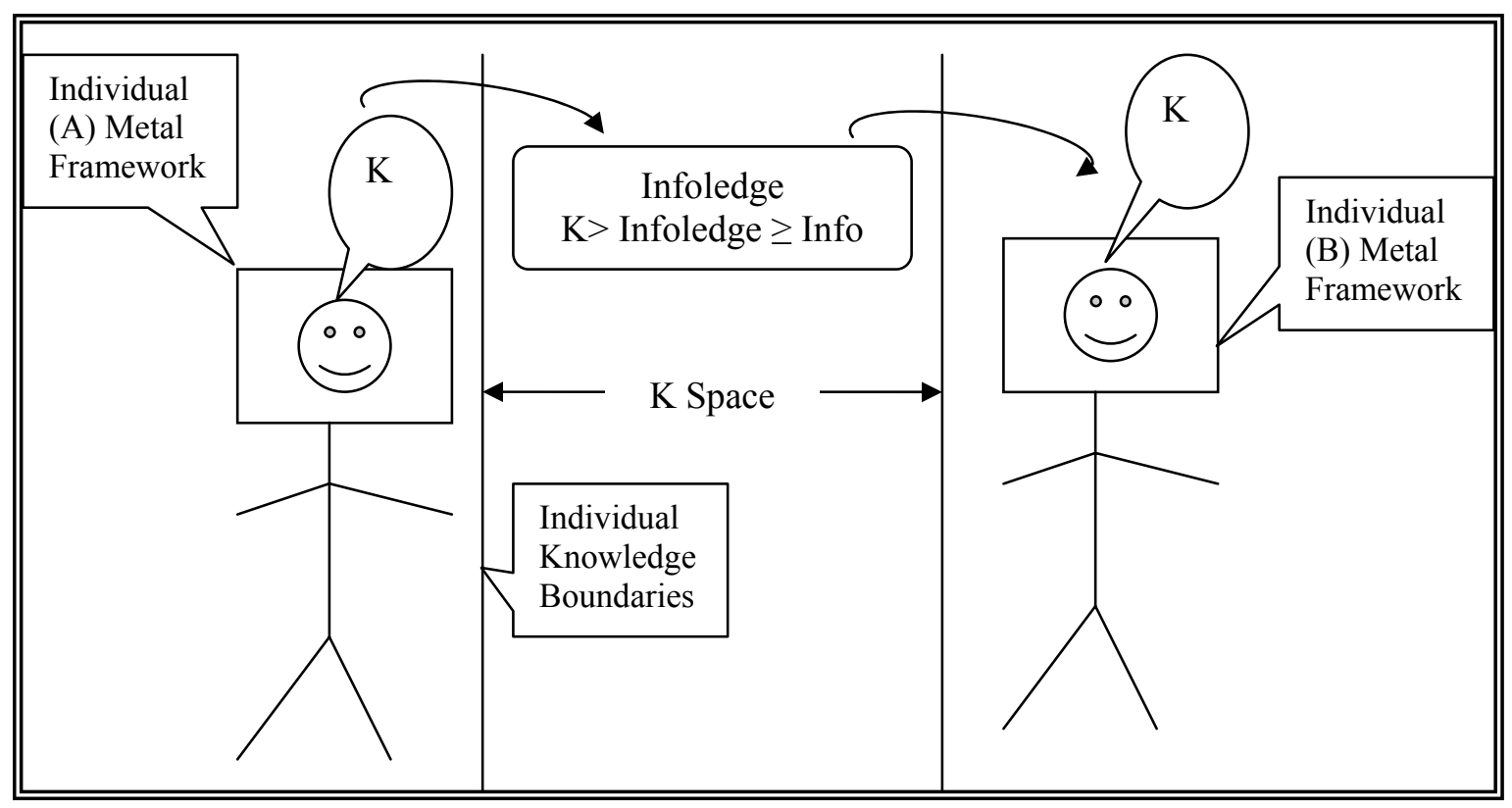

Figure 7: Knowledge conversion and infoledge illustration

At the end of externalization stage, the sender expresses his/her knowledge and the receiver obtains a full meaning statement, which is known as information or infoledge given the absorptive capacity of the receiver and its location on the data-wisdom spectrum (see Figure 1). Let us examine the analogy represented by the flow of a certain concept in the Figure 6 to study the behavior of explicit knowledge. To begin with, we will identify the symbols used:

E.K: explicit knowledge and INF: information F: it represents the pushing force for the transition process of explicit knowledge to information. It is related to the sender's belief of the receiver's ability to realize the concept. The relation between the pressing effect (sender belief) and a receiving interface (receiver ability), mathematically can be depicted:

Fs: Sender belief toward receiver understandability

Fr: Receiver ability to express his understandability

This $\mathrm{F}$ amount determines the speed with which the transition process will be conducted. However, this amount is also determined by the sender intuition ensuing result from Eq (3), related to a certain concept toward the receiver.

The understandability can be expressed mathematically as follows:

Understandability a[1 / Complexity], where a denotes to proportional relationship.

Where the complexity is strongly related to the knowledge type, i.e., trivial knowledge, base knowledge, as the complexity increases, the understandability will decrease. The important thing to be noted from Figure 8 is that during the conversion process there is a shrinking indication of explicit knowledge and expanding one for information. What these indications mean? Any knowledge (of any type) built from information received and combined with the mental framework of its owner; mathematically this can be represented by the following equation:

Knowledge $=($ Information + Intuition $)$

So the difference between knowledge and information is the intuition. Once the knowledge owner starts expressing his knowledge (articulation process), the intuition will decrease and the receiver 
will comprehend the concept as information. By this concept, information can be expressed mathematically as follows:

Lim Explicit knowledge = Information

$\mathrm{t}=0$

Again, the time $t=0$ is the time when the explicit knowledge has been completely externalized of its owner and become either data, information or infoledge from the receiver point of view. This is visualized by the dotted line in Figure 8. In the same context, Maqsood et al. (2004) asserted that the first element involved in the human information process is the progress of knowledge creation of the perception of the event, and then the use of memory to give this perception recognition. They identify the perception concept as a selective process where certain amounts of information from the outside are selected because not all of the information coming in can be incorporated. They maintained that perception is affected by factors such as attitudes, values, stress and a person's background. The perception concept is highly related to the infoledge concept. To clarify this point let us examine Figure 8:

It can be noted from Figure 8, that the force $\mathrm{F}$ defined earlier acts by of completing the explication process, so at the end of this stage the explicit knowledge range related to the concept under

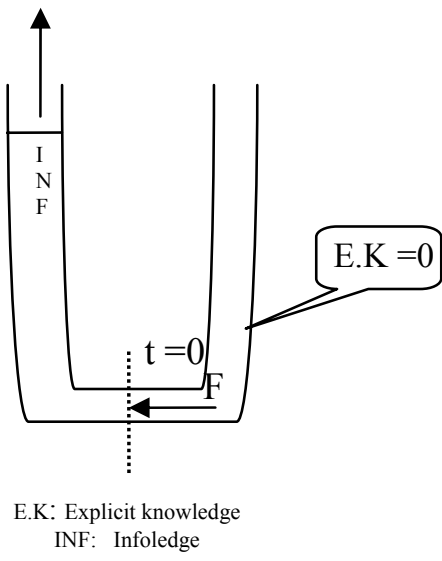

Figure 8: Conversion at time $=0$ consideration will be empty, denoted by "E.K=0". In this context, it can be said that at this point the intuition of the sender will be close to zero value since the intuition is not transferred with the information. Consequently, it can be claimed that the point $(0,0)$ is where intuition respectively is at the point which define the information. Taking into consideration the above definition of time $\mathrm{t}=0$, Jamieson and Hyland (2006) implicitly pointed to the infoledge concept through the preference in which the decision maker's shape was intuitively based on the information presented to them. Also, Okafar and Osuagwa (2006) and Maqsood et al. (2004) stated that the quality of tacit knowledge is usually affected by certain factors like perception, cognitive styles, ...etc. Figure 9 shows the way how the tacit knowledge of any human matures. By examining Eq (0), it can be concluded that the mathematical integration model best fit the knowledge maturation process. Again, the maturation process ends with the formation of tacit knowledge within the receiver's mind with respect to a specific context (see Figure 9). So equation (3) is valid for the tacit knowledge of the receiver, which can be mathematically represented by the following equation:

$\mathrm{t} \rightarrow \mathrm{t} 2$

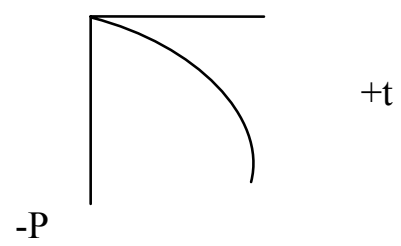

Figure 9: maturing (internalizing) process

The way how to reach the tacit knowledge was presented earlier in $\mathrm{Eq}(0)$. 
For any point in any region

Lim intuition $=$ Wisdom, $\mathrm{f}=$ infinity

$\rightarrow \mathrm{f}$
$\mathrm{Eq}(8) \mathrm{t}$

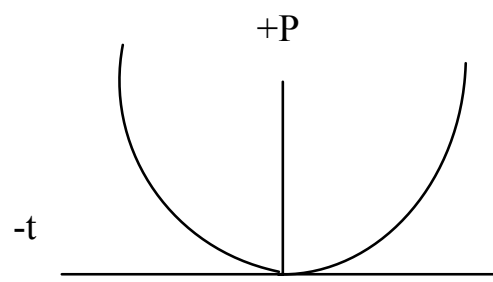

Figure 10: self Knowledge conversion

Figure 10 shows the case when the human itself start forming a new knowledge from the expressed knowledge (information). Figure 11 illustrates the overall conversion process with reference to the data-wisdom spectrum discussed across the paper.

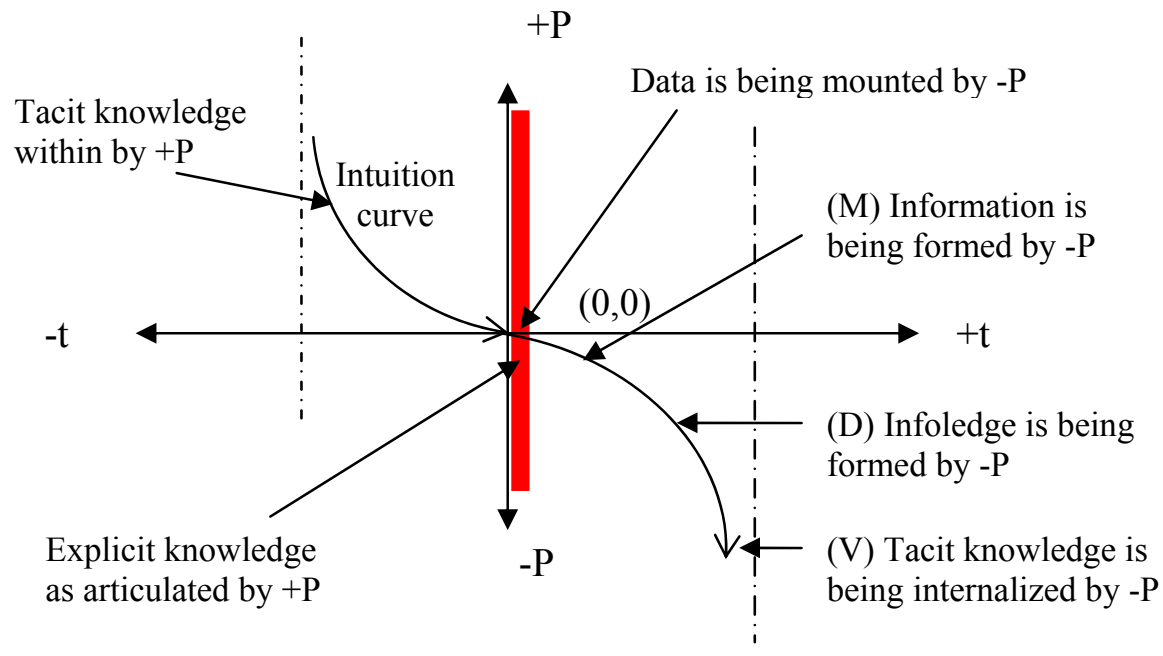

Figure 11: Overall conversion knowledge process

\section{Conclusion}

This paper presents a mathematical interpretation and representation of the knowledge conversion process of knowledge transfer into information. Furthermore, the representation includes the introduction and definition of new concept, namely, Infoledge. A mathematical formulation was considered for knowledge maturity, intuition and understandability. This view of knowledge transfer process represents an addition to the formulation of the conversion and transfer process of information and knowledge in order to provide a context of analysis and understanding that is more systematic, scientific and manageable.

\section{References}

Alkhaldi, F. M. (2003). An integration of information technology, culture of knowledge transfer and innovative work environment in support of organisational knowledge creation activities. Unpublished $\mathrm{PhD}$, University of Huddersfield, UK

Alkhaldi, F. M. (2005). Spectrum of knowledge conversion: The theory of "Infoledge". Unpublished Manuscript, Arab Academy for Banking and Financial Science, Amman, Jordan

Bailey, C., \& Clarke, M. (2000). How do managers use knowledge about knowledge management? Journal of Knowledge Management, 4(3), 235 
Boisot, M., \& Griffith, D. (2001). To own or to possess? Competence and the challenge of appropriability. In R. Sanchez (Ed.), Knowledge management and the organizational competence (pp.210-226). London: Oxford University Press.

Choo, C. W. (1998). The knowing organization. Oxford University Press.

Davenport, T., \& Prusak, L. (1998). The working knowledge. Boston, MA: Harvard Business School Press.

Falzon, L., Zhang, L., \& Davies, M. (2000). A policy analysis approach to operational level course of action analysis. 15th International Command and Control Technology Symposium, Canberra, Australia.

Fernie, S., Green, S.D., Weller, S.J. \& Newcombe, R. (2003). Knowledge sharing: Context, confusion and controversy. International Journal of Project Management, 21(3), 177-186.

Huseman, R., \& Goodman, J., (1999). Leading with knowledge. London: Sage.

Jamieson, K., \& Hyland, P. (2006). Good intuition or fear and uncertainty: The effect of bias on information systems selection decisions. Informing Science Journal, 9, 49-68. Available at http://inform.nu/Articles/Vo19/v9p049-069Jamieson60.pdf

Knapp, E. M. (1998). Knowledge management. Business \& Economic Review, 44(4), 3-6.

Kogut, B., \& Zander, U., (1996). What firms do? Coordination, identity, and learning. Organizational Science, 7(5): 502-518.

Liebeskind, J.P. (1996). Knowledge, strategy, and the theory of the firm. Strategic Management Journal, 17 (Winter), 93-107.

Maqsood, T., Finegan, A.D., \& Walker, D.H. (2004). Biases and heuristics in judgment and decision making: The dark side of tacit knowledge. Issues in Informing Science and Information Technology, 1, 295-301. Available at http://articles.iisit.org/050maqso.pdf

Maturana, H.R., \& Varela, T.J. (1980). Autopoeisis and Cognition. London: Reidl.

Nelson, R., \& Winter, S., (1982). An evolutionary theory of economic change. Cambridge, MA, USA: Harvard University Press.

Nonaka, I. (1994). A dynamic theory of organizational knowledge creation. Organizational Science, 5(1), 14-37.

Nonaka, I., \& Takeuchi, H. (1995). The knowledge creating company. Oxford University Press.

Nonaka, I., \& Takeuchi, H. (1996). A theory of organizational knowledge creation. International Journal of Technology Management, 11(7/8), 833-845.

Okafor, E.C., \& Osuagwu, C.C. (2006). The underlying issues in knowledge elicitation. Interdisciplinary Journal of Information, Knowledge, and Management, 1, 95-108. Available at http://ijikm.org/Volume1/IJIKMv1p095-107Okafor.pdf

Polanyi, M. (1966). The tacit dimension. London: Routledge and Kegan Paul.

Salas, S.L. \& Etgen, G.J. ( 1998 ). Salas and Hille's calculus: One and several variables (8th edition). John Wiley \&Sons.

Sanchez, R. (2001). Managing knowledge into competence: The five leaning cycles of the competent organisation. In R. Sanchez (Ed.), Knowledge management and the organisational competence (pp.337). London: Oxford University Press. 


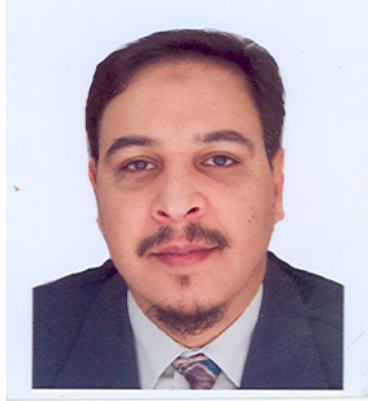

\section{Biographies}

Dr. Firas M. Alkhaldi, is an Assistance professor of knowledge Management, He holds a BA and MA in Applied Economics from WMU, USA, and a PhD in Knowledge Management from Huddersfield University, UK. He is a Certified e-business Consultants and a KM Professional. He is the Dean of Scientific Research at the Arab Academy for Banking and Financial Sciences and a professor in the faculty of information Systems and Technology, AABFS. He is affiliated with a number of international professional societies on KM and E-business. He had a leadership role in the design and implementation of many academic programs at the undergraduate and graduate level including a doctoral program. His research interest are in knowledge conversion and transfer, organizational knowledge theory, knowledge culture, Innovative work environment, human and Social implications of Enterprise systems (ERP, CRM, SCM). His work appears in number international Journals and conferences

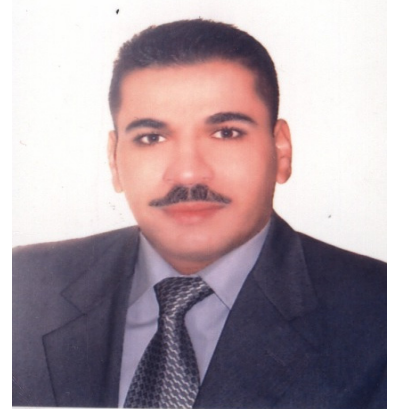

Mohammad Olaimat holds his Bachelors degree in mechanical engineering from Jordan university for science and technology, Jordan, and he received a Masters Degree in computer information systems from Arab Academy for Banking and Financial Sciences in 2006. His research interest is in knowledge representation, knowledge management, supply chain management, software engineering industry, business process reengineering, and secured organization. He has five published papers. 